\title{
Scenario Construction and Its Implications for International Relations Research
}

\author{
Dong-ho Han
}

(Institute of Foreign Affairs and National Security) 〈CONTENTS〉

I . Introduction

II. What is the Scenario Methodology

1. Key Terms in the Scenario Methodology

2. Process of Scenario Analysis

III. Why the Study of International Politics Needs Scenario

Methodology
1. The Need for Multiple Perspectives

2. The Problem of Prediction and Scenario Thinking as a Possible Solution

3. Bridging the Gap between Policy Makers and Scholars in the Field

IV . Conclusion

- Key words : Scenario methodology, future uncertainties, eclectic approach, prediction, theory and practice

\section{【ABSTRACT】}

This article intends to introduce scenario methodology into the field of international relations (IR) in a systematic way. After clarifying what scenario methodology is and how it is presented, it argues that the scenario methodology is one of the most effective methods to connect theory to practice, thereby leading to a better understanding of future world events. This argument is based on exploring the implications of scenario method in the field of IR with regard to three issue areas - an eclectic approach to world politics, the issue of prediction in the social sciences and scenario analysis as a solution for that, and the connection between theory and practice. Overall, scenario methodology urges policy makers to make a decision on the pragmatic and problem-solving basis in a real world of policy making. 


\section{I . Introduction}

How do we assess future possibilities with existing data and information? Do we have a systematic approach to analyze the future events of world politics? Given various theoretical ideas for predicting and analyzing future events in the field of international relations (IR), to understand these events properly it is important both to consider all plausible outcomes and to think through a relevant theory, or a combination of each major theory, in connection with those outcomes. This article aims to explain the scenario methodology and why it is adequate to provide a useful understanding of future world events.

After clarifying the scenario methodology and its core components, and its processes and purposes, it explores the importance and implications of the scenario method in the field of IR - the need for multiple perspectives, the problem of prediction and scenario thinking as a possible solution, and the bridge between theory and practice. Finally, it concludes with the role of scenario analysis in the policy-making process.

\section{What is the Scenario Methodology ${ }^{1)}$}

Herman Kahn, a pioneer of the scenario method, in his famous 1962 book Thinking about the Unthinkable, argued that the decision makers in the United States should think of, and prepare for, all possible sequences of events with regard to nuclear war with the Soviet Union. ${ }^{2)}$ Using scenarios and connecting them with various war games, Kahn showed the importance of thinking ahead in time and using the scenario method based upon imagination for the future. ${ }^{3)}$

1) For a brief history of the scenario method, see Peter Schwartz, The Art of the Long View (N ew York: Currency Doubleday, 1991), pp. 7-9. For an explanation of the origins of scenario thinking, see D iana Scearce, Katherine Fulton, and the G lobal Business N etwork community, What If?: The Art of Scenario Thinking for N onprofits (Emeryville, CA: G lobal Business N etwork, 2004), p. 11.

2) In response to the question why we need to explore "the unthinkable," Kahn asserts that "The serious, even if temporary, consideration of extreme examples jerks us out of our peaceful world and stimulates our imaginations." Herman Kahn, Thinking about the U nthinkable (N ew York: H orizon Press, 1962), p. 185. 
According to Kahn and his colleagues, scenarios are "attempts to describe in some detail a hypothetical sequence of events that could lead plausibly to the situation envisaged." ${ }^{4)}$ Similarly, Peter Schwartz defines scenarios as "stories about the way the world might turn out tomorrow, stories that can help us recognize and adapt to changing aspects of our present environment." ${ }^{5)}$ Given these definitions of scenarios, ${ }^{6}$ for the purpose of this research, I refer to the scenario-building methodology as a means by which people can articulate different futures with trends, uncertainties, and rules over a certain amount of time. Showing all plausible and possible stories and clarifying important trends, scenario thinking enables decision makers to make an important decision at the present time.

What is the main purpose of the scenario methodology? According to Paul Schoemaker, the ultimate goal of scenario-based planning is to see the future extensively in terms of its fundamental dynamics including trends, continuities, discontinuities, and uncertainties. In other words, scenario methodology aims at building a shared framework in which strategic thinking, diversity, and more sensitivity to external changes and opportunities is encouraged. ${ }^{7)}$ Pierre Wack also suggests that the purpose of scenario analysis is to have a series of scenarios illustrating the major driving forces, their interactions, and the critical uncertainties. ${ }^{8}$ Peter Schwartz put forth the desired role of scenario building in a real world of decision making as the

3) For a detailed explanation of scenarios and their presentations, see Ibid., pp. 150-164.

4) Herman Kahn and Anthony J. W iener, The Year 2000: A Framework for Speculation of the N ext Thirty-Three Years (N ew York: The H udson Institute, Inc., 1967), p. 262.

5) Peter Schwartz (1991), op. cit., p. 3. According to Peter Schwartz, the term scenario has its origin in the theatrical term "scenario" which refers to "the script for a film or play."

6) Since Kahn's introduction of the scenario method into strategic planning, a number of authors have tried to define what scenarios are. For instance, Robert Lempert defines scenarios as "carefully constructed stories about the future intended to help people make better decisions in the face of uncertainty." See Robert Lempert, "C an Scenarios H elp Policymakers Be Both Bold and Careful?" in Francis Fukuyama (eds.), Blindside: H ow to Anticipate Forcing Events and W ild Cards in Global Politics (N ew York: Basic Books, 2007), p. 110. Also Louis Albrechts depicts scenarios as "a narrative description of a possible state of affairs or development over time of a place" in his, "C reativity as a D rive for Change," Policy Planning 4-3 (2005), p. 255.

7) Paul J. H. Schoemaker, "Scenario Planning: A Tool for Strategic Thinking," Sloan M anagement Review 36-2 (1995), p. 28.

8) Pierre W ack, "Scenarios: Shooting the Rapids," H arvard Business Review 63-6 (N ovemberD ecember 1985b), p. 146. 
efforts of building scenarios ahead of time intended to encourage today's better decision rather than tomorrow's forecasting. ${ }^{\text {') }}$

\section{Key Terms in the Scenario Methodology}

The core of the scenario method lies in enabling policy makers to reach a critical decision at the present time based on thinking about all plausible future possibilities. Key concepts in the scenario method include: driving forces, predetermined elements, critical uncertainties, wild cards and scenario plot lines. ${ }^{10)}$

Driving forces are defined as "the causal elements that surround a problem, event or decision," which could be many factors, including those "that can be the basis, in different combinations, for diverse chains of connections and outcomes." "11) Schwartz defines driving forces as "the elements that move the plot of a scenario, that determine the story's outcome."12) In a word, driving forces constitute the basic structure of each scenario plot line in the scenariomaking process.

Predetermined elements refer to "events that have already occurred or that almost certainly will occur but whose consequences have not yet unfolded." ${ }^{13)}$ Predetermined elements are "givens" which could be safely assumed and understood in the scenario-building process. Although predetermined elements impact outcomes, they do not have a direct causal impact on a given outcome. ${ }^{14)}$ In other words, predetermined elements could be an underlying cause for any given outcome.

Critical uncertainties "describe important determinants of events whose

9) Peter Schwartz (1991), op. cit., p. 9.

10) For a general explanation of the components of scenario planning, see lbid., pp. 100-117.

11) Steven Bernstein, et al., "God G ave Physics the Easy Problems: Adapting Social Science to an U npredictable W orld," European J ournal of I nternational Relations 6-1 (2000), p. 55.

12) Peter Schwartz (1991), op. cit., pp. 101-102.

13) Pierre W ack, "Scenarios: U ncharted W aters Ahead," H arvard Business Review 63-5 (September-O ctober 1985a), p. 77. For more elaboration of the nature of predetermined elements, see Peter Schwartz, Inevitable Surprises: Thinking Ahead in a Time of T urbulence (N ew York: Gotham Books, 2003), pp. 5-8.

14) The relationship between predetermined elements and outcomes can be understood as the one between underlying cause and effects. Although underlying cause does not directly impact the outcome like proximate cause does, that does not mean that underlying cause has no impact on the outcome. In fact, it does implicitly. 
character, magnitude or consequences are unknown." ${ }^{15)}$ Exploring critical uncertainties lies at the heart of scenario construction in the sense that the most important task of scenario analysts is to discover the elements that are most uncertain and most important to a specific decision or event. ${ }^{16)}$

Wild cards are "conceivable, if low probability, events or actions that might undermine or modify radically the chains of logic or narrative plot lines." ${ }^{177}$ In John Peterson's terms, wild cards are "not simple trends, nor are they byproducts of anything else. They are events on their own. They are characterized by their scope, and a speed of change that challenges the

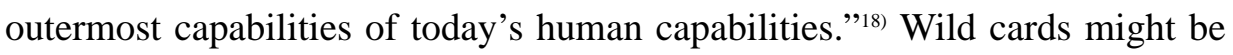
extremely important in that in the process of scenario planning their emergence could change the entire direction of each scenario plot line.

A scenario plot line is "a compelling story about how things happen" and it describes "how driving forces might plausibly behave as they interact with predetermined elements and different combinations of critical uncertainties. ${ }^{\prime 19)}$ Narratives and/or stories are an essential part of the scenario method due to the identical structure of analytical narratives and scenarios: "both are sequential descriptions of a situation with the passage of time and explain the process of events from the base situation into the situation questioned." ${ }^{20)}$

\section{Process of Scenario Analysis ${ }^{21)}$}

Scenario analysis begins with the exploration of driving forces, including

15) Steven Bernstein, et al., op. cit., p. 55.

16) Steven Weber, "Prediction and the M iddle East Peace Process," Security Studies 6-4 (1997), p. 173.

17) Steven Bernstein, et al., op. cit., p. 58.

18) John L. Peterson, O ut of the Blue: Wild Cards and O ther Big Future Surprises, $\mathrm{H}$ ow to Anticipate and Respond to Profound Change (Arlington, Virginia: The Arlington Institute, 1997), p. 1.

19) Steven Bernstein, et al., op. cit., p. 56. For practical applications of plausible plots for scenario-planning, see Peter Schwartz (1991), op. cit., pp. 135-162.

20) Paul D ragos Aligica, "Analytic N arratives and Scenario Building," Futures Research Q uarterly 19-2 (Summer 2003), p. 61.

21) In the literature of the scenario methodology, the terms such as scenario thinking, scenario analysis and scenario planning are being used to refer to the use of the scenario method in general. In this paper, I will use these terms interchangeably. 
some uncertainties. Robert Lempert succinctly summarized the scenario process as follows: "scenario practice begins with the challenge facing the decisionmakers, ranks the most significant driving forces according to their level of uncertainty and their impact on trends seemingly relevant to that decision, and then creates a handful of scenarios that explore different manifestations of those driving forces." ${ }^{22}$ ) As Lempert points out, the scenario process comprises several steps such as identifying the issue, specifying driving forces based on considering both the level of uncertainty and the impact on trends, and articulating and creating possible and plausible scenarios. Figure 1 illustrates the scenario process.

\section{Figure 1. The Scenario-Building Process}

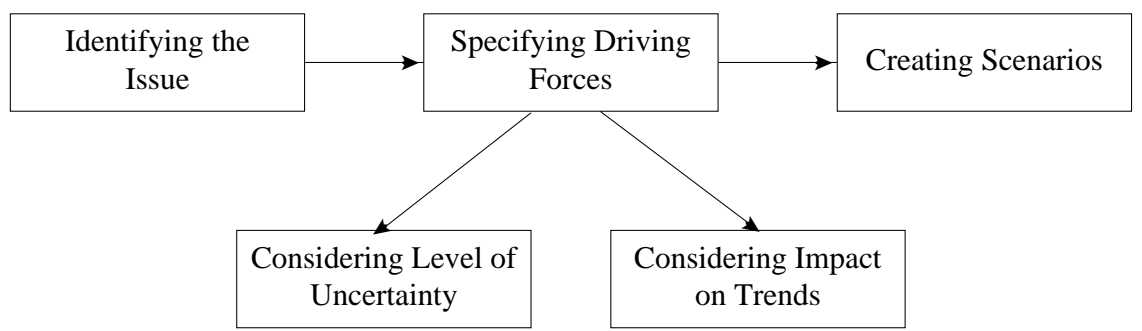

Source: Robert Lempert, "Can Scenarios H elp Policymakers Be Both Bold and Careful?" in Francis Fukuyama (eds.), Blindside: How to Anticipate Forcing Events and Wild Cards in Global Politics (W ashington, D .C.: Brookings Institution Press, 2007), p. 112.

According to different sources such as that of the Global Business Network $(\mathrm{GBN}){ }^{23)}$ with the aim to clarify and identify driving forces, predetermined elements, and critical uncertainties, the scenario-building process consists of five phases: orient, explore, synthesize, act, and monitor. The first step, Orient, would be to clarify the central issue and have it as a guide post to the remaining four phases. The second step, Explore, is to figure out important

22) Robert Lempert, op. cit., p. 112.

23) Different authors may put the process in a slightly different way. For instance, see Bill Ralston and Ian Wilson, The Scenario-Planning H andbook: A Practitioner's Guide to D eveloping and U sing Scenarios to D irect Strategy in Today's U ncertainties (Indiana: Thomson/South-W estern, 2006). Ralston and Wilson suggest three stages of scenario construction: "setting the ground for making scenarios," "gathering available data and identifying key factors," and "writing the story lines for the scenarios." Each stage has different steps such as deciding the case, identifying the important drivers, clarifying critical uncertainties, writing the story lines, etc. 
drivers which may or may not be critical in the process of scenario building. The third step in scenario thinking, Synthesize, is a selecting process of driving forces, clarifying the two or three important factors that would impact the focal issue. The fourth step, Act, is to urge people to act based upon identified driving forces and scenarios. The fifth step, Monitor, is the process of keeping decision makers alert to any shift and open to a continued strategic conversation. ${ }^{24}$

Figure 2. The Scenario Process of GBN

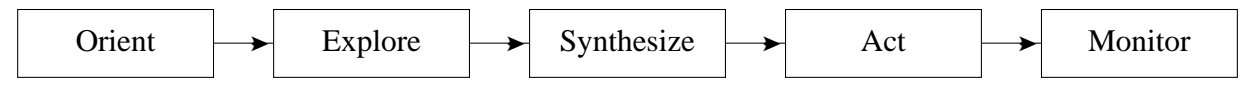

Source: Diana Scearce, Katherine Fulton, and the Global Business N etwork community, What If?: The Art of Scenario Thinking for N on profits (Emeryville, CA: G lobal Business N etwork, 2004), pp. 24-33.

Exploring future uncertainties thoroughly is one of the most important factors in scenario analysis. Kees van der Heijden argues that in the process of separating "knowns" from "unknowns" analysts could clarify driving forces because the process of separation between "predetermineds" and uncertainties demands a fair amount of knowledge of causal relationships surrounding the issue at stake. ${ }^{25}$ ) Thus, in scenario analysis a thorough understanding of critical uncertainties leads to a well-established knowledge of driving forces and causal relations. ${ }^{26)}$

The case of the Mont Fleur scenario project of South Africa could be a good illustration of the successful process of scenario building. Facing various uncertainties for the future of South Africa as of 1991, the Mont Fleur scenario team began to ask three important questions about the result of ongoing negotiations, the degree of political transition, and the sustainability of policies of the South African democratic government. By asking proper and critical questions, this scenario team tried to figure out what the central

24) Diana Scearce, Katherine Fulton, and the Global Business N etwork community, op. cit., pp. 24-33.

25) Kees van der H eijden, Scenarios. The Art of Strategic Conversation, 2nd ed. (N ew Sussex: John Willey \& Sons, Ltd, 2005), p. 5.

26) $0 \mathrm{n}$ this point Peter Schwartz suggests that predetermined elements and critical uncertainties cannot always be understood as a separate category but sometimes are overlapped. See Peter Schwartz (1991), op. cit., p. 108. 
issue is regarding the future of South African political landscape (Identifying the central issue). And also by asking these questions, the Mont Fleur scenario team sorted out important drivers such as the ongoing negotiation process and democratization (Specifying driving forces). Specifically, each question this scenario team posed is directly linked to upcoming outcomes that this team designed (Creating scenarios).

The first question, "Will negotiations result in a settlement?" is closely related to the possibility of the emergence of a non-representative government (Ostrich) in South Africa if it is negatively answered. The second question is relevant with the pace and extent of the political transition in South Africa: "Will the transition be rapid and decisive?" The question concerning the character of South African political transition opens up the opportunity to think about the rise of an incapacitated government (Lame Duck) if the issue of political transition could not be properly managed by the government and various participants in public and private spheres. The third question is: "Will the democratic government's policies be sustainable?" This third question produces two related future outcomes. First, if South Africa's democratic government could adopt and implement sustainable democratic policies, the future of South Africa would be explained by such key words as inclusive democracy and growth (Flight of the Flamingos). Second, if policies are not sustainable, collapse is inevitable (Icarus) given the complexity and vulnerability of the political environment in South Africa. Figure 3 illustrates the Mont Fleur scenario process.

Figure 3. The Mont Fleur Scenario Project

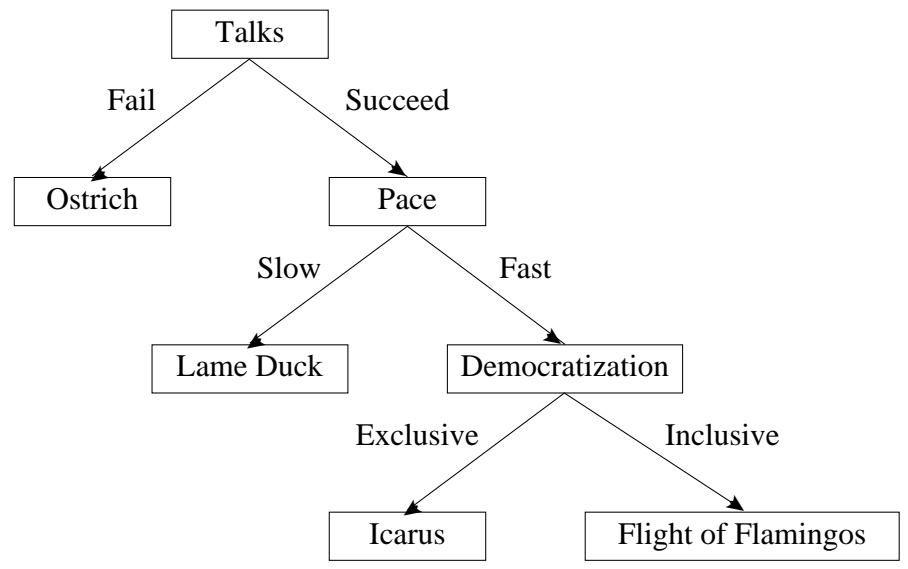


Based on the above figure, in fact considering three questions and subsequent four outcomes are in some sense commonsensical given the South African political situation at that time. The more important is, however, to figure out and explore the pace and degree of political changes the then South African government faced in terms of democratization in its polity. Here comes in the importance of a thorough understanding of critical uncertainties based on a basic research of predetermined elements in the scenario process. The case of the Mont Fleur scenario project shows that it is only after understanding given critical uncertainties more deeply that it is possible to connect each critical uncertainty with various outcomes and/or scenarios such as, in the Mont Fleur scenario case, Flight of the Flamingos (inclusive democracy and growth), Lame Duck (Incapacitated government), Ostrich (non-representative government), and Icarus (Macro economic populism). ${ }^{27)}$

In this context, it should be emphasized that scenario building is more than just organizing future uncertainties; rather, it is a thorough understanding of uncertainties, thereby distinguishing between something clear and unclear in the process of decision making. ${ }^{28)}$ As Pierre Wack has pointed out, "By carefully studying some uncertainties, we gained a deeper understanding of their interplay, which, paradoxically, led us to learn what was certain and inevitable and what was not." In other words, a careful investigation of raw uncertainties helps people figure out more "critical uncertainties" by showing that "what may appear in some cases to be uncertain might actually be predetermined - that many outcomes were simply not possible." ${ }^{29}$

The process of sorting out raw uncertainties and figuring out critical uncertainties also reveals the difference between learning scenarios and decision scenarios. In the scenario-building process Schoemaker

27) These four outcomes showed the future routes of South African democracy in an effective way. For instance, the name I carus showed one possible future of South Africa's democratization - a short-lived one that would burn out - like Icarus flying too high and having his wings melted by the sun. For a detailed explanation of this project and its effects on the future of South Africa, see Global Business N etwork, "The M ont Fleur Scenarios: W hat will South Africa be like in the year 2002?" The D eeper N ews 7-1 (1996), pp. 1-22.

28) For an excellent account of scenario planning and its working process based upon an analysis of the four quadrants of the matrix, see C hantell Ilbury and Clem Sunter, The M ind of a F ox: Scenario Planning in Action (Cape T own: H uman \& Rousseau / T afelberg, 2001).

29) Pierre W ack (1985a), op. cit., p. 76 and p. 78. 
distinguishes between learning scenarios and decision scenarios. ${ }^{30)}$ The former presents a basic combination of critical uncertainties while the latter shows more articulated routes of various futures based on critical uncertainties explored. ${ }^{31)}$ In other words, decision scenarios intend to present more plausible future scenarios whereas learning scenarios aim to show all possible scenarios. ${ }^{32)}$ The ultimate goal here is to transform learning scenarios into decision scenarios. ${ }^{33)}$ In the scenario process, scenarios "should cover a wide range of possibilities and highlight competing perspectives, while focusing on interlinkages and the internal logic within each future." ${ }^{34)}$ By revealing core elements of the predicted future, scenarios might change people's minds and thinking. This is because the main function of scenario analysis is to challenge deeply ingrained assumptions of political leaders, corporate executives, and even ordinary citizens, and help them recognize and check these assumptions. In this way decisions could be made on the basis of a careful investigation of several possibilities which often are easily ignored

30) Schoemaker basically suggests ten steps in scenario analysis: defining the scope, identifying the major stakeholders, identifying basic trends, identifying key uncertainties, constructing initial scenario themes, checking for consistency and plausibility, developing learning scenarios, identifying research needs, developing quantitative models and evolving toward decision scenarios. See Paul J. H. Schoemaker, op. cit., pp. 28-30.

31) In the process of scenario construction, most scenario experts suggest, some critical uncertainties could become predetermined elements after a careful investigation of given uncertain factors. In other words, "raw" critical uncertainties at the first stage of scenario analysis should be carefully "explored." In a later stage of scenario construction, "real" critical uncertainties that have not been identified as predetermined elements could be the basis of decision scenarios which consist of various plausible future routes.

32) The difference between these two kinds of scenarios could be closely linked to the discourse of different approaches to scenarios such as the incremental approach and the inductive approach. For a more detailed account of different approaches, see Diana Scearce, Katherine Fulton, and the Global Business N etwork community, op. cit., p. 31. D espite some differences in composing scenarios, both approaches aim at transforming learning scenarios into decision scenarios and, in the process, plausible future scenarios become clearer based on the discussion on various possible future scenarios.

33) W ack emphasizes the importance of decision scenarios compared to "first-generation scenarios" although he does not use the term learning scenarios explicitly. See Pierre W ack (1985a), op. cit., p. 76. D espite all the importance of decision scenarios, learning scenarios also play an essential role in the scenario process in the sense that the purpose of constructing learning scenarios is "to identify themes that are strategically relevant and then organize the possible outcomes and trends around them." in Paul J. H. Schoemaker, op. cit., p. 29.

34) Paul J. H. Schoemaker, op. cit., p. 30. 
due to the hindrance of untested assumptions in decision makers' minds. ${ }^{35)}$

As already revealed in analysis of process of the scenario methodology, one of the advantages of the scenario method lies in its connection to the real world of policy making. Thus in some sense the task of constructing scenarios is nothing more than a problem-solving strategy at its core. Due to its highly applicable characteristics in real world affairs, scenario analysis could be an excellent tool to anticipate an unknown future and achieve practical purposes ahead of time. Since scenario methodology attempts not only to solve the present problem, but also to make it possible for policy makers to make better decisions in the future, the promise of scenario methodology could be that by revealing the present clearly and shedding light on it in a wholly new perspective, it allows decision makers to make critical decisions with new possibilities and implications of various alternative futures. ${ }^{36)}$ Thus the aim and process of scenario planning are perfectly matched with the practical needs found in the arenas of the military, business, and the economy.

\section{Why the Study of International Politics Needs Scenario Methodology}

In the field of IR a few scholars have reevaluated the importance of scenario analysis as a social science methodology. ${ }^{37)}$ These scholars contend that the scenario-building method could make a unique contribution to IR research because of the alternatives to a "scientific" approach it offers to mainstream IR theorizing.

Janis Gross Stein and her colleagues' work on the future of the IsraeliPalestinian conflict is a good example of the scenario methodology in

35) Allen $\mathrm{H}$ ammond, Which W orld?: Scenarios for the 21st Century (W ashington, D .C.: Island Press, 1998), p. 14.

36) Ibid., p. 14.

37) Relevant works are Steven W eber, op. cit., pp. 167-179; Janis Gross Stein, et al., "Five Scenarios in the Israel-Palestinian Relationship in 2002," Security Studies 7-4 (1998), pp. 195-208; Steven Bernstein, et al., op. cit., pp. 43-76. For a recent effort to explain scenario analysis in reference to regional affairs, see Ayse Betul Celik and Andrew Blum, "Future Uncertain: U sing Scenarios to Understand Turkey's Geopolitical Environment and its Impact on the Kurdish Q uestion," Ethnopolitics 6-4 (N ovember 2007), pp. 569-583. 
practice. In 1998, these scholars tried to clarify the trends surrounding future Israeli-Palestinian relations, using forward reasoning and scenario construction. In the process of applying scenario methodology they produced five scenarios regarding the future of the Israel-Palestinian relationship based on such factors as negotiated agreement, the status quo, and Palestinian independence or autonomy. They posited that the domestic political structure of Israel is a key component in determining the future of the IsraeliPalestinian relationship in the region. ${ }^{38}$ For instance, one of their scenarios no negotiated settlement, territorial status quo, and Palestinian autonomy is based on the combinations among deteriorating Israeli public opinion on the prospect of the peace process with the Palestinian authority, Palestinian leaders' decision to use violence against Israel with support from Hamas elements in domestic politics, and subsequent justification of non-dealing with the Palestinian National Authority (PNA) of the Likud government of Israel.

These scholars' scenario construction work is dependent on indentifying domestic political factors in Israel and Palestine and their interactions regarding the Israel-Palestinian relationship. A key speculation from this group comes from their diverse theoretical perspectives and their regional expertise, which make it possible to think about the future in a more systematic way. After producing several scenarios, this group of IR scholars notes,

The scenarios themselves make clear that there are connections among the stories, that the plot lines can flow through one another. These scenarios do not represent sealed universes, but interconnected contingent worlds, where forces can drive the process from one scenario to another. We need to identify these loops and links, and specify as clearly as possible the kinds of forces and contingencies that would move the relationship from one path to another. ${ }^{39)}$

By emphasizing the interconnectedness of factors and their outcomes these IR scholars have shown the practical use of the scenario method with a real

38) Janis G ross Stein, et al., op. cit., p. 197.

39) I bid., p. 211. 
world example.

Another recent example in the field would be Celik and Blum's scenariobased analysis of Turkey's security environment and its impact on the Kurdish question. Concerning the future of Turkey, they posited four scenarios: stable pluralism, peaceful polarization, the internal struggle, and competing nationalisms. These scenario outcomes are based on the discussions on such factors as the impact of both the EU access process and developments in northern Iraq ${ }^{40)}$ By showing a clear impact of the EU process and the existence of Kurds in northern Iraq on Turkey's future political landscape with respect to the resolution of the Kurd question, Celik and Blum effectively extrapolated the evolving dynamics of different ethnic groups and their interactions in the Turkish state and its adjacent region using scenario terms.

Given this backdrop, using the scenario method into the IR field has important implications for the development of innovative methodologies to predict world events. This rationale is all the more relevant in the field given the failure of the prediction of the end of the Cold War twenty years ago. After observing the abrupt end of the Cold War, Cold War historian John Lewis Gaddis pointed out that "we tend to bias our historical and our theoretical analyses too much toward continuity... we rarely find a way to introduce discontinuities into theory, or to attempt to determine what causes them to happen." ${ }^{{ }^{11)}}$ How can we solve the problem of the difficulty - even the impossibility - of predicting important world events while still preserving some progress of our "scientific" theory development in the discipline? In the conclusion of his 1992 article, Gaddis noted that "good scientists... make use of all the tools at their disposal in trying to anticipate the future. That includes not just theory, observation, and rigorous calculation, but also narrative, analogy, paradox, irony, intuition, imagination, and - not least in importance - style." ${ }^{42)}$ Even if he does not clearly use terms like scenario method or scenario construction, Gaddis seems to have an idea similar to scenario thinking when he mentions important tools to enable us to make an every effort to anticipate the future.

40) Ayse Betul Celik and Andrew Blum, op. cit., pp. 572-579.

41) John Lewis Gaddis, "International Relations Theory and the End of the Cold War," International Security 17-3 (W inter 1992-93), p. 52. (Emphasis added).

42) Ibid., p. 58. 
Among several factors that contribute to scenario making, imagination, for example, plays a crucial role in making sense of futures studies, although it has long been ignored by "traditional" social science research programs. Kahn emphasizes the role of imagination, arguing that imagination "has always been one of the principal means for dealing in various ways with the future, and the scenario is simply one of many devices useful in stimulating and disciplining the imagination." ${ }^{43)}$ With the power of imagination, thinking about all plausible and relevant factors in preparation for an unknown future seems to be all the more important given the increasing nature of uncertainty in future world politics. ${ }^{44)}$

Proponents of the scenario method suggest forward reasoning as a useful tool in making scenarios of future events in international politics. However, the emphasis on forward reasoning does not necessarily mean that scenario thinking simply ignores the lessons of the past. Rather, by emphasizing looking forward, scenario analysis enables policy makers to "march into the future looking backward, guided by the accumulated lessons of past experience." ${ }^{45)}$ Similarly, some IR scholars assert the advantage of forward reasoning - thinking forwardly "opens our analyses to the possibilities of alternative futures, but forces discipline in tracing likely paths created by important drivers in combination with significant uncertainties"46) It is critical to distinguish between important driving forces which mostly make a course of future events and some uncertainties which are important yet impossible to figure out at the present moment. Given this backdrop, advocates for scenario analysis in the discipline argue that analyzing critical unknowns and assessing different possibilities are becoming more and more essential in studying international politics. In the following pages, I will explore the reasons we need the scenario methodology in the field of IR.

43) H erman Kahn and Anthony J. W iener, op. cit., p. 264.

44) Francis Fukuyama, "The Challenges of Uncertainty: An Introduction," in Francis Fukuyama (eds.), Blindside: H ow to Anticipate Forcing Events and Wild Cards in Global Politics (N ew York: Basic Books, 2007), pp. 1-6.

45) Allen Hammond, op. cit., p. 14.

46) Steven Bernstein, et al., op. cit., p. 69. 


\section{The Need for Multiple Perspectives}

The scenario methodology opens the possibility of the simultaneous use of diverse theoretical insights in the field. One of the advantages of scenario thinking lies in its eclectic characteristic in the process of research. Scenario thinking in international relations dictates that we should use our theoretical diversity as much as possible to solve important empirical puzzles. This implication is particularly important in the IR field because many IR scholars have long tried to point to the limit of strictly using a certain theoretical framework in explaining and analyzing world events. For instance, Peter Katzenstein and Nobuo Okawara suggest an eclectic approach as a promising way of reasoning in IR research, arguing that analytical eclecticism is a great tool to understand a complex political world. Rather than holding to one specific approach and its own assumptions, taking a problem-driven approach to analyze international affairs is more fruitful in terms of understanding international dynamics and suggesting relevant policy implications. ${ }^{47)}$ In this context, Katzenstein and Okawara assert that "Extolling, in the abstract, the virtues of a specific analytical perspective to the exclusion of others is intellectually less important than making sense of empirical anomalies and stripping notions of what is 'natural' of their intuitive plausibility." "48) In a word, eclectic explanations help policy makers and researchers alike take a more flexible approach to real-world problems that IR research basically aims to resolve, thereby coping with complexities in the world in a more efficient way.

Along the same line of this reasoning, some scholars have tried to analyze the future prospect for international politics by using a synthesis of the existing body of international relations theory. Aaron Friedberg's work on the future of U.S.-China relations provides a good example of how to use a diverse body of IR theories to understand upcoming events. In explaining future U.S.-China relations, Friedberg tries to mix each school of thought in IR and produce plausible future prospects based on six sorts of synthesis: liberal optimists, realist pessimists, liberal pessimists, realist optimists, constructivist optimists, and constructivist pessimists. ${ }^{49)}$ According to

47) Peter J. Katzenstein and N obuo O kawara, "Japan, Asia-Pacific Security, and the Case for Analytical Eclecticism," International Security 26-3 (W inter 2001-2002), pp. 153-185.

48) Ibid., p. 154.

49) Aaron L. Friedberg, "The Future of U.S.-China Relations: Is Conflict Inevitable?" 
Friedberg, each theoretical framework has a clear limit in analyzing complex realities of world politics, thus not providing comprehensive prospects for future U.S.-China relations. He wrote: "Driven by the desire to construct parsimonious theories and to establish the preponderance of one paradigm or school, scholars have often been inclined to adopt an all-or-nothing attitude, asserting the overwhelming importance of the causal mechanisms central to their preferred paradigm while downplaying or ignoring the possible significance of others." ${ }^{50)}$

To overcome the limits of using parsimonious theoretical approaches, Friedberg suggests it is necessary to synthesize all relevant theories and approaches to reveal any possibilities of future U.S.-China relationship. Even if Friedberg never explicitly calls for the necessity of using scenarios in working on his thesis, what he basically did in his article very much conforms to scenario analysis based on articulating any possible outcomes of future Sino-American relations derived from existing assumptions, theories, and approaches. He points out, "As they try to peer into a future that is necessarily obscured from their view, today's political scientists and foreign policy analysts also need to try to find ways of apprehending the full array of causal forces that are at work, assessing their relative strengths and thinking about the ways in which they are likely to combine with one another." ${ }^{51)}$

Some scholars, however, emphasize the advantage of the parsimonious use of IR theory in predicting future world events. In his article about the future of Europe, for instance, John Mearsheimer points out that to better understand the future we need to understand the past and learn how to apply the lesson of the past into unfolding history: the main task of IR scholars who are willing to project into future uncertainties is "to decide which theories best explain the past, and will most directly apply to the future; and then to employ these theories to explore the consequences of probable scenarios." ${ }^{.2)}$ Then based on his theoretical application he predicted the future of Europe as the full potential possibility of conflicts between nations. Despite rigorous application of his realist theoretical lens to European affairs after the Cold War,

International Security 30-2 (Fall 2005), pp. 12-39.

50) Ibid., p. 10.

51) Ibid., p. 12.

52) John J. M earsheimer, "Back to the Future: Instability of Europe after the Cold War," International Security 15-1 (Summer 1990), p. 9. 
Mearsheimer's analysis of future balance of power in Europe does not hold given the present Europe is facing a relatively peaceful era based on economic cooperation and social integration under the European Union system.

As Mearsheimer reminds us, in the IR field the dominant type of theory used for the analysis of the future is just to use one paradigmatic approach and provide the most plausible upcoming event based on that specific theoretical reasoning. In a word, using theory parsimoniously is the most common approach in current IR scholarship. Even if using theories to predict one linear course of events is clear and straightforward, it is risky given that in the process of applying these theories there is always some possibility for the rise of uncertainties and surprises. ${ }^{53)}$ Moreover, parsimonious theoretical explanations for future world events often fail with the passage of time.

At this point it is correct to point out that the lack of proper method to analyze future events in the field of IR leads to the necessity of an analytical tool that has pragmatic and eclectic characteristics. ${ }^{54}$ Because most advocates of scenario analysis in other fields defend its utility specifically in view of multiple perspectives, the use of scenario method in a more systematic way could stimulate a more rigorous analysis of unfolding future events in the IR field. ${ }^{55}$

The focus on multiple perspectives of scenario planning is all the more clear given critical objectives of scenario method. According to Steven Weber, the scenario methodology has three objectives: 1. "to draw out fundamental theoretically driven assumptions about the major driving forces that impinge on events," 2. "to develop and analyze interaction possibilities among those

53) For the necessity of a careful analysis of surprises and uncertainties in the study of world affairs, see Peter Schwartz and D oug Randall, "Ahead of the Curve: Anticipating Strategic Surprise," in Francis Fukuyama (eds.), Blindside: How to Anticipate Forcing Events and Wild Cards in Global Politics (N ew York: Basic Books, 2007), pp. 93-108. For the importance of historical lessons to interpret today's challenges of surprising events in the context of America's national security policy, see John Lewis Gaddis, Surprise, Security, and the American Experience (C ambridge, M A: H arvard U niversity Press, 2004).

54) For a recent account of the necessity of pragmatism in IR research and methodology, see Jorg Friedrichs and Friedrich Kratochwil, "On Acting and Knowing: H ow Pragmatism Can Advance International Relations Research and M ethodology," International Organization 63-4 (Fall 2009), pp. 701-731.

55) For the explanation of scenario analysis in association with using multiple perspectives, see Global Business N etwork, Scenarios: An Explorer's Guide (The Hague, the N etherlands: Shell International, 2008), pp. 16-19; D iana Scearce, Katherine Fulton, and the Global Business N etwork community, op. cit., p. 14; Kees van der H eijden, op. cit., pp. 131-151. 
driving forces," and, 3. "to organize that complexity into a small or moderate number of possible future scenarios." ${ }^{56)}$ In a word, Weber emphasizes the importance of identifying basic assumptions and arguments of each theoretical exercise and then connecting them into a set of possible story lines in analyzing upcoming events. Therefore, the very purpose of the scenariobuilding methodology calls for the necessary connections among a variety of theoretical approaches in the field of IR.

\section{The Problem of Prediction and Scenario Thinking as a Possible}

\section{Solution}

In addition to providing the eclectic foundation for using multiple theoretical lenses in the field, the building of scenarios in analyzing world events could solve the difficulty of the matter of prediction in social science research. Predicting the future is not an easy task. In the field of IR, researchers making predictions tend to focus on their parsimonious assumptions and arguments drawn from a specific school of thought in which they are engaged. They present the rigor of their theoretical explanations by refuting other theoretical perspectives and make a prediction based on the victory of their theories over other approaches. The problem, however, is that making a prediction based on established theories and approaches can easily be disrupted as unexpected contingencies like wild cards occur. ${ }^{57)}$ In other words, in a real world of politics too many uncertain factors are involved and thus politics can be understood as a non-linear process toward unpredictable outcomes. ${ }^{58)}$ There are many real cases of the difficulty of prediction in social science. The failure to predict the end of the Cold War is one of them. ${ }^{59)}$ During the Cold War era, many scholars explored the causes of U.S.-Soviet confrontation and predicted that the Cold War would last quite a long time. ${ }^{60)}$

56) Steven W eber, op. cit., pp. 171-172.

57) See J ohn L. Peterson, op. cit.; Peter Schwartz (2003), op. cit. For an earlier discussion of this topic, see Gabriel A. Almond and Stephen J. Genco, "Clouds, Clocks, and the Study of Politics," World Politics 20-4 (1977), pp. 489-522.

58) Robert Jervis, System Effects: Complexity in Political and Social Life (N J: Princeton U niversity Press, 1997), especially pp. 29-91.

59) John Lewis Gaddis, op. cit., pp. 1-58.

60) Among those who predicted the stability of the Cold War system, for instance, Kenneth W altz made his argument of the durability of the Cold W ar based upon the logic of 
These scholars' arguments for the durability of the Cold War were simply dismissed along with such upcoming events as the fall of the Berlin Wall in 1989 and the demise of the Soviet Union in 1991.

Despite the difficulty of prediction in world politics some factors are relatively clear and easy to figure out, regardless of one's theoretical background. For instance, it is hard to deny that U.S. power and influence is one of the critical factors in understanding the present world. In this sense, Robert Jervis is right when he argues that "Since the United States is the most influential power in the world, to predict the future of world politics requires us to predict the future of American foreign policy." ${ }^{161)}$ When it comes to the study of a specific region in world politics, however, things are more complicated. While understanding important variables such as U.S. foreign policy helps us to analyze more accurately the future course of international politics in general, in order to predict the future dynamics of regional politics in particular something more is needed. ${ }^{62)}$ Given the complexity of regional issues making a prediction is still not an easy task.

Given this backdrop some scholars argue that prediction in the social sciences could be possible if we had some critical information regarding specific issues. Among others, Bruce Bueno de Mesquita makes his case for the possibility of prediction, arguing that if we know critical information such as identified policy makers with some stakes, their policy preferences (i.e. what they say they want), how salient the issue at stake is among these actors, and how influential these policy makers are in terms of changing and shaping the outcomes, then we can predict upcoming policy decisions and thus overall political outcomes based upon these "influential" policy makers' strategic interactions with one another. ${ }^{63)}$ Bueno de Mesquita's prediction comes from

bipolarity derived from his neorealist approach to international politics. See Kenneth $\mathrm{N}$. W altz, "T he Stability of a Bipolar W orld," D aedalus 93-3 (1964), pp. 881-909.

61) Robert Jervis, "The Future of World Politics: Will It Resemble the Past?" International Security 16-3 (W inter 1991-92), p. 41.

62) For the importance of understanding regional contexts in order to better understand world politics in general, see Fred $\mathrm{H}$ alliday, The $\mathrm{M}$ iddle East in International Relations: Power, Politics and I deology (Cambridge: C ambridge U niversity Press, 2005), especially pp. 1-17.

63) For a recent account of this line of reasoning, see Bruce Bueno de M esquita, The Predictioneer's Game: U sing the Logic of Brazen Self-Interest to See and Shape the Future ( $N$ ew York: Random H ouse, 2009). Regarding necessary information in prediction, especially see pp. 49-50. 
the logic of how decision makers make various policy decisions in a gametheoretic term, with the support of a computer-based simulation model. In other words, by using mathematical techniques such as computer simulation models in predicting the future Bueno de Mesquita's argument is mostly dependent on rational choice theory which assumes "self-interested" people and dictates their "strategic interactions." ${ }_{64)}$

Even if some scholars' efforts to develop predictive tools such as that of Bueno de Mesquita are successful in predicting some emerging properties, it cannot be denied that as the time span increases, there would be more possibility of increasing number of discontinuities and contingencies in the process of research. These predictive efforts appear to assume that politics are a linear course of action and people are always rational in their interactions with others. This might be true when time span is short enough to justify these underlying assumptions. However, this computer-based predictive enterprise does not seem to effectively deal with upcoming surprises and unexpected contingencies. ${ }^{65)}$ In this sense, these predictions may sometimes be just estimates which are hard to project for the long term.

The scenario method seems to be a good fit particularly in this regard; that is, in order to cope effectively with upcoming surprises and uncertainties it is essential to rehearse as many future possibilities as one can and scenario thinking facilitates this reasoning process. Despite sharing some similarities with other predicting tools such as a computer simulation model, the scenario method is fundamentally different from these methods. As one advocate for scenario analysis points out, scenarios are "more than just the output of a complex simulation model. Instead they attempt to interpret such output by identifying patterns and clusters of the millions of possible outcomes a computer simulation might generate... Hence, scenarios go beyond objective analyses to include subjective interpretations." ${ }^{66)}$ Scenario methodology promises not only to help predict important events but also to stimulate the process of learning and reperceving existing assumptions, thereby facilitating to adapt to a new environment.

64) For a more general explanation of the necessity and accuracy of prediction in the social sciences based on a game theoretic model, see Bruce Bueno de M esquita, Predicting Politics (Columbus: The 0 hio State U niversity Press, 2002), pp. 9-14 and pp. 71-77.

65) Francis Fukuyama (eds.), op. cit.; John L. Peterson, op. cit.

66) Paul J. H. Schoemaker, op. cit., p. 27. 
It is true that a number of advocates of scenario methodology emphasize that point prediction is not a primary goal of the scenario-based analysis. This does not mean, however, that scenario methodology is incompatible with other predictive methods. In fact, scenario methodology really helps to predict upcoming events by providing a variety of possible and plausible plot lines. By this methodology, decision makers could see the chain of logic in unfolding events more clearly with the passage of time and thus have a more confidence to predict emergent property. My point here is that rather than stick to such particular research goal as point prediction, scenario methodology could give policy makers sort of flexibility to revise and reevaluate their predictive enterprise as the process of learning based on multiple scenario analysis. ${ }^{67)}$ Hence, given the difficulty of prediction in the social sciences and the complexity of international politics in general, and area studies in particular, there seems to be enough rationale for IR scholars and regional experts or policy makers to use scenario thinking to analyze the logic of upcoming events, equipped with various insights derived from a variety of IR theories and approaches. By switching the goal of its research program as a whole from prediction to learning, scenario analysis could set the foundation for reconciling the tendency of measuring and observing the "hard" reality with a more "softening" way of interpretation and imagination. ${ }^{68}$

\section{Bridging the Gap between Policy Makers and Scholars in the Field}

Because of the possibility of an eclectic approach and the flexibility of the goal of its research program (i.e. from prediction to learning) the scenario method makes it possible for policy makers to make a decision at the present time based on considering various alternative futures and to deal with

67) M ost literature on scenario planning emphasizes the critical aspect of learning rather than point prediction on the part of decision makers using scenario analysis.

68) In the IR field, one of the meaningful efforts to show the importance of learning can be found in Hermann and Choi's 2007 article exploring experts' changing attitudes on certain issue areas through the lens of the learning process over time. Advocating the advantages of using various scenarios, $\mathrm{H}$ ermann and Choi emphasize the importance of learning based on combining several factors to anticipate future events in international politics. Richard H ermann and Jong Kun Choi, "From Prediction to Learning: O pening Expert's M inds to U nfolding H istory," International Security 31-4 (Spring 2007), pp. 132161. 
uncertainties in a more systematic fashion ${ }^{69)}$ In other words, as a result of scenario analysis contemplating different future courses, policy makers could be better prepared for an unknown future in the decision-making process.

One of the recurring criticisms of IR scholarship is that scholars tend to focus too much on "big" theories and generalizations and "rigorous" methodologies to stay away from a real world of global politics and it can be thus said that the necessity of connecting IR theories to the policy making world is higher than ever before. ${ }^{70)}$ Given this backdrop the scenario method could provide some alternatives for the overflow of grand paradigmatic debate in the discipline and contribute to more focus on empirical puzzles in world politics, which policy makers eagerly seek to solve. Since scenario thinking emphasizes a more process-oriented and problem-oriented research methodology, policy makers could take advantage of the scenario-thinking process as their problem-solving toolkit. ${ }^{71)}$ More specifically, thanks to scenario analysis, decision makers will be able to "develop their own feel for the nature of the system, the forces at work within it, the uncertainties that underlie the alternative scenarios, and the concepts useful for interpreting key data." ${ }^{22}$

For the previously mentioned reasons, it is necessary to introduce the

69) The benefits of the scenario method on bridging the gap between theory and practice are manifest even in an undergraduate course for first year IR students. Simpson and Kaussler report that using simulations, roles plays, and some conflict scenarios is an effective pedagogical tool for students with little knowledge of IR. Regarding scenario exercise for undergraduate students they wrote: "The aim of this exercise is for students to acquire factual information on the background, political situation, actors involved, ideologies and constituents informing respective policies and domestic politics of any given conflict and then apply it to the fictional scenario." Archie W. Simpson and Bernd Kaussler, "IR T eaching Reloaded: U sing Films and Simulations in the T eaching of International Relations," International Studies Perspectives 10-4 (2009), p. 415.

70) For recent discussion of this subject matter, see M ichael N icholson, "W hat's the U se of International Relations," Review of International Studies 26 (2000), pp. 183-198; Stephan M. Walt, "The Relationship between Theory and Policy in International Relations," Annual Review of Political Science 8 (2005), pp. 23-48. For an earlier discussion on this topic, see Alexander L. George, Bridging the Gap: Theory and Practice in Foreign Policy (W ashington, D.C.: U nited States I nstitute of Peace Press, 1993).

71) Again, the pragmatic characteristic of the scenario-planning process seems to be becoming an essential ingredient of international relations research given the demand for diverse pragmatic approaches in the field. See Jorg Friedrichs and Friedrich Kratochwil, "O n Acting and Knowing: $\mathrm{H}$ ow Pragmatism Can Advance International Relations Research and M ethodology," International O rganization 63 (Fall 2009), pp. 701-731.

72) Pierre W ack (1985b), op. cit., p. 140. 
scenario method to the field of IR in a more systematic way and the present article aims to be one of these efforts. Scenario analysis, of course, does not solve all the problems that the IR field faces, such as the need of multiple approaches, the limit of predictive enterprise, and the gap between theory and practice. Rather, it is more reasonable to say that scenario-based forward thinking could be compatible with any other theoretical approach in the field insomuch as futures studies are concerned. In this sense, some advocates of scenario thinking in the IR field are quite correct when they assert that "[scenario thinking] is a complementary toolkit that has promise for generating new ideas and arguments, broadening the range of causal relationships that we study, and tracking the evolution of world politics through periods of discontinuous change, in ways that promise to better over time both understanding and action., ${ }^{{ }^{3} 3}$

\section{Conclusion}

The advantage of scenario analysis lies in its succinctness and clarity of analyzing upcoming important global and/or regional issues. A clear understanding of the matter at stake makes solutions easier to be found. Analysis based on the scenario method helps scholars and policy makers alike identify the relevant issues and provide effective solutions for them. Scenario analysis promises that although the future is uncertain, policy makers could effectively deal with upcoming future events by sorting out important drivers pushing toward specific outcomes. In the field of international relations, by allowing the synthesis of theoretical insights from each school of thought, scenario construction could be an alternative methodology with which policy makers can explore various possibilities and outcomes and make a policy decision accordingly.

73) Steven Bernstein, et al., op. cit., p. 71. 


\section{REFERENCES}

Albrechts, Louts. "Creativity as a Drive for Change." Policy Planning 4 -3. 2005, pp. 247-269.

Aligica, Paul D. "Analytic Narratives and Scenario Building." Futures Research Quarterly 19-2. 2003, pp. 57-71.

Almond, Gabriel A. and Stephen J. Genco. "Clouds, Clocks, and the Study of Politics." World Politics 20-4. 1977, pp. 489-522.

Bernstein, Steven, Richard Ned Lebow, Janice Gross Stein, and Steven Weber. "God Gave Physics the Easy Problems: Adapting Social Science to an Unpredictable World." European Journal of International Relations 6-1. 2000, pp. 43-76.

Blum, Andrew. "The Futures of Conflict: Exploring the Use of Comparative Scenarios in Track II Peacebuilding." International Studies Perspectives 6. 2005, pp. 342-358.

Bueno de Mesquita, Bruce. "The End of the Cold War: Predicting an Emergent Property.” Journal of Conflict Resolution 42-2. 1998, pp. 131-155. . Predicting Politics. Columbus: The Ohio State University Press, 2002.

. The Predictioneer's Game: Using the Logic of Brazen Self-Interest to See and Shape the Future. New York: Random House, 2009.

Celik, Ayse Betul and Andrew Blum. "Future Uncertain: Using Scenarios to Understand Turkey's Geopolitical Environment and its Impact on the Kurdish Question.” Ethnopolitics 6-4. 2007, pp. 569-583.

Friedberg, Aaron L. "The Future of U.S.-China Relations: Is Conflict Inevitable?" International Security 30-2. 2005, pp. 7-45.

Friedrichs, Jorg and Friedrich Kratochwil. "On Acting and Knowing: How Pragmatism Can Advance International Relations Research and Methodology.” International Organization 63. 2009, pp. 701-731.

Fukuyama, Francis. eds. Blindside: How to Anticipate Forcing Events and Wild Cards in Global Politics. Washington, D.C., Brookings Institution Press, 2007.

. "The Challenges of Uncertainty: An Introduction." In Francis Fukuyama. eds. Blindside: How to Anticipate Forcing Events and Wild Cards in Global Politics. Washington, D.C.: Brookings Institution Press, 2007, pp. 109-119.

Gaddis, John Lewis. "International Relations Theory and the End of the Cold War.” International Security 17-3. 1992/93, pp. 5-58. 
Galer, Graham and Kees van der Heijden. "The Learning Organization: How Planners Create Organizational Learning." Marketing Intelligence and Planning 10-6. 1992, pp. 5-12.

George, Alexander L. Bridging the Gap: Theory and Practice in Foreign Policy. Washington, D.C.: United States Institute of Peace Press, 1993.

Geus, Arie de. "Planning as Learning." Harvard Business Review 66-2. 1988, pp. 70-74.

. "Foreword: Modelling to Predict or to Learn?" European Journal of Operational Research 59. 1992, pp. 1-5.

Ghamari-Tabrizi, Sharon. The Worlds of Herman Kahn: The Intuitive Science of Thermonuclear War. Cambridge, Massachusetts: Harvard University Press, 2005.

Global Business Network. "Education and Community: Four Scenarios for the Future of Public Education." The Deeper News 6-1. 1995, pp. 1-34. . "The Mont Fleur Scenarios: What will South Africa be like in the year 2002?" The Deeper News 7-1. 1996, pp. 1-22.

. Scenarios: An Explorer's Guide. The Hague, the Netherlands: Shell International, 2008.

. "The Future of Economic Development in Central America." The Deeper News 5. 2009, pp. 3-4.

Halliday, Fred. The Middle East in International Relations: Power, Politics and Ideology. Cambridge: Cambridge University Press, 2005.

Hammond, Allen. Which World?: Scenarios for the 21st Century. Washington, D.C.: Island Press, 1998.

Herrmann, Richard K. and Jong Kun Choi. "From Prediction to Learning: Opening Experts' Minds to Unfolding History." International Security 31-4. 2007, pp. 132-161.

Ilbury, Chantell and Clem Sunter. The Mind of a Fox: Scenario Planning in Action. Cape Town: Human \& Rousseau / Tafelberg, 2001.

Jervis, Robert. "The Future of World Politics: Will It Resemble the Past?" International Security 16-3. 1991/92, pp. 39-73.

. System Effects: Complexity in Political and Social Life. Princeton: Princeton University Press, 1997.

Kahn, Herman. Thinking about the Unthinkable. New York: Horizon Press, 1962.

. Thinking about the Unthinkable in the 1980s. New York: Simon and Schuster, 1984.

Kahn, Herman and Anthony J. Wiener. The Year 2000: A Framework for 
Speculation of the Next Thirty-Three Years. New York: The Hudson Institute, Inc, 1967.

Katzenstein, Peter J. and Nobuo Okawara. "Japan, Asian-Pacific Security, and the Case for Analytical Eclecticism." International Security 26-3. 2001/02, pp. 153-185.

Lempert, Robert. "Can Scenarios Help Policymakers Be Both Bold and Careful?" In Francis Fukuyama. eds. Blindside: How to Anticipate Forcing Events and Wild Cards in Global Politics. Washington, D.C.: Brookings Institution Press, 2007, pp. 109-119.

Mearsheimer, John J. "Back to the Future: Instability in Europe after the Cold War." International Security 15-1. 1990, pp. 5-56.

. "The False Promise of International Institutions." International Security 19-3. 1995, pp. 5-49.

. The Tragedy of Great Power Politics. New York: Norton, 2001.

Moravcsik, Andrew. "Taking Preferences Seriously: A Liberal Theory of International Politics." International Organization 51-4. 1997, pp. 513553.

Morgan, David L. "Paradigms Lost and Pragmatism Regained: Methodological Implications of Combining Qualitative and Quantitative Methods." Journal of Mixed Methods Research 1-1. 2007, pp. 48-76.

Neumann, I. B. and Erik F. Overland. "International Relations and Policy Planning: The Method of Perspectivist Scenario Building." International Studies Perspectives 5. 2004, pp. 258-277.

Nicholson, Michael. "What's the Use of International Relations." Review of International Studies 26. 2000, pp.183-198.

Peterson, John L. Out of the Blue: Wild Cards and Other Big Future Surprises, How to Anticipate and Respond to Profound Change. Arlington, Virginia: The Arlington Institute, 1997.

Ralston, Bill and Ian Wilson. The Scenario-Planning Handbook: A Practitioner's Guide to Developing and Using Scenarios to Direct Strategy in Today's Uncertainties. Indiana: Thomson/South-Western, 2006.

Scearce, Diana, Katherine Fulton, and the Global Business Network community. What If?: The Art of Scenario Thinking for Nonprofits. Emeryville, California: Global Business Network, 2004.

Schoemaker, Paul J. H. "Scenario Planning: A Tool for Strategic Thinking." Sloan Management Review 36-2. 1995, pp. 25-40.

Schwartz, Peter. The Art of the Long View. New York: Currency Doubleday, 
1991.

. Inevitable Surprises: Thinking Ahead in a Time of Turbulence. New York: Gotham Books, 2003.

Schwartz, Peter and Doug Randall. "Ahead of the Curve: Anticipating Strategic Surprise." In Francis Fukuyama. eds. Blindside: How to Anticipate Forcing Events and Wild Cards in Global Politics. Washington, D.C.: Brookings Institution Press, 2007, pp. 93-108.

Simpson, Archie W. and Bernd Kaussler. "IR Teaching Reloaded: Using Films and Simulations in the Teaching of International Relations." International Studies Perspectives 10-4. 2009, pp. 413-427.

Stein, Janis Gross, et al. "Five Scenarios in the Israeli-Palestinian Relationship in 2002." Security Studies 7-4. 1998, pp. 195-208.

Tangredi, Sam J. "All Possible Wars? Toward a Consensus View of the Future Security Environment, 2001-2025." McNair Paper 63. Washington, D.C.: Institute for National Strategic Studies, National Defense University, 2000.

. Futures of War: Toward A Consensus View of the Future Security Environment, 2010-2035. Newport: Alidade Press, 2008.

van der Heijden, Kees, et al. The Six Sense: Accelerating Organizational Learning with Scenarios. West Sussex: John Wiley \& Sons, Ltd, 2002. . Scenarios: The Art of Strategic Conversation. 2nd ed. New Sussex: John Willey \& Sons, Ltd, 2005.

Wack, Pierre. "Scenarios: Uncharted Waters Ahead." Harvard Business Review 63-5. 1985a, pp. 73-89.

. "Scenarios: Shooting the Rapids." Harvard Business Review 63-6. 1985b, pp. 139-150.

Walt, Stephan M. "The Relationship between Theory and Policy in International Relations." Annual Review of Political Science 8. 2005, pp. 23-48.

Waltz, Kenneth N. "The Stability of a Bipolar World.” Daedalus 93-3. 1964, pp. 881-909.

Weber, Steven. "Prediction and the Middle East Peace Process." Security Studies 6-4. 1997, pp. 167-179. 